\title{
GAMBARAN TINGKAT KELEMBABAN KULIT PADA PASIEN GAGAL GINJAL KRONIK DI RUANG HEMODIALISA RSUD BULELENG
}

\author{
Daryaswanti, Putu Intan \\ Akademi Keperawatan Kesdam IX/Udayana \\ *Korespondensi: intan_daryaswanti@,akperkesdamudayana.ac.id
}

\begin{abstract}
Background: Etiology of pruritus uremic has not yet been found specifically, but there are risk factors of the pruritus such as dry skin, reduced pruritogenic transpidermal elimination, hyperparathyroid, high calcium, magnesium and phosphate levels. Pruritus is a common and sad symptom that affects patients with chronic kidney disease. Purpose: to describe the skin moisture level in patients with Chronic Kidney Failure who undergo Hemodialysis in the Hospital of Buleleng. Method: This research is a quantitative research using descriptive method design. The population of this study was CRF patients who underwent regular HD at Buleleng Hospital. Sampling using simple random sampling technique with a total of 52 respondents. Respondents studied were CRF patients who underwent regular HD twice a week with a description of characteristics including age, sex, education, occupation and length of HD. Result: showed that the majority of respondents $(38.4 \%)$ were in the category of 30-45 years old with a greater number of male respondents (69.2\%). Most of the respondents' education levels were in secondary education $(42.3 \%)$ and respondents did not work as many as 10 respondents $(19.2 \%)$. Furthermore, the length of HD is mostly for $0-5$ years, which is as much as $75 \%$. the skin moisture level of CRF patients undergoing Hemodialysis in Buleleng General Hospital found that all respondents obtained dry skin $(100 \%)$. Patients who undergo HD for approximately 5 years have experienced dry skin. Conclusion: Chronic kidney failure can cause changes in the sweat glands and oil glands which cause the skin to lose its natural ability to moisturize itself. This condition can also be caused by metabolic changes in CRF, which are interrelated with the fluid volume of patients undergoing dialysis.
\end{abstract}

Keywords : chronic renal failure, hemodialysis, skin moisture

\begin{abstract}
ABSTRAK
Latar Belakang: Pruritus uremik sampai saat ini belum ditemukan etiologi secara spesifik, tetapi terdapat beberapa faktor penyebab pruritus seperti kulit kering, berkurangnya eliminasi transpidermal faktor pruritogenik, hiperparatiroid, peningkatan kadar kalsium, magnesium dan fosfat yang tinggi. Pruritus adalah gejala umum dan menyedihkan yang mempengaruhi pasien dengan penyakit ginjal kronis. Tujuan penelitian ini untuk mengetahui gambaran tingkat kelembaban kulit pada pasien Gagal
\end{abstract}


Ginjal Kronik yang menjalani Hemodialisis di RSUD Buleleng. Metode: Penelitian ini merupakan penelitian kuantitatif dengan menggunakan desain metode deskriptif. Populasi penelitian ini adalah pasien GGK yang menjalani HD regular di RSUD Buleleng. Pengambilan sampel menggunakan teknik simple random sampling dengan jumlah 52 responden. Responden yang diteliti adalah pasien GGK yang menjalani HD regular 2x seminggu dengan gambaran karakteristik mencakup usia, jenis kelamin, pendidikan, pekerjaan dan lama HD. Hasil: penelitian menunjukkan bahwa mayoritas responden $(38,4 \%)$ berada pada kategori berusia 30-45 tahun dengan jumlah responden laki-laki lebih banyak $(69,2 \%)$. Jenjang pendidikan responden sebagian besar berada pada pendidikan menengah $(42,3 \%)$ dan responden tidak bekerja sebanyak 10 responden $(19,2 \%)$. Selanjutnya, lama HD sebagian besar selama 0-5 tahun yaitu sebanyak $75 \%$. Simpulan: Hasil penelitian ini menunjukkan $100 \%$ pasien GGK yang menjalani HD memiliki kulit kering, karena Gagal ginjal kronik dapat menyebabkan perubahan pada kelenjar keringat dan kelenjar minyak yang menyebabkan kulit menjadi kehilangan kemampuan alami untuk melembabkan diri.

Kata Kunci : Gagal Ginjal Kronik, Hemodialisa, Kelembaban Kulit

\section{PENDAHULUAN}

Komplikasi umum pada pasien Gagal Ginjal Kronik (GGK) yang menjalani Hemodialisis (HD) yaitu pruritus uremik. Pruritus uremik muncul dengan keluhan gatal sehari-hari yang umumnya menyerang punggung, wajah dan lengan (Simonsen et al., 2017). Rasa gatal muncul pada 6 bulan setelah awal dialisis dan biasanya meningkat dengan lamanya pasien menjalani dialisis (Roswati, 2013). Pruritus uremik sampai saat ini belum ditemukan etiologi secara spesifik, tetapi terdapat beberapa faktor penyebab pruritus seperti kulit kering, berkurangnya eliminasi transpidermal faktor pruritogenik, hiperparatiroid, peningkatan kadar kalsium, magnesium dan fosfat yang tinggi. Pruritus adalah gejala umum dan menyedihkan yang mempengaruhi pasien dengan penyakit ginjal kronis. Menentukan penyebab, perawatan yang efektif dan tindakan pencegahan untuk gatal adalah salah satu dari 10 prioritas (Combs, Teixeira, \& Germain, 2015).

Prevalensi kejadian pruritus uremik dilaporkan sebanyak 22\% - 84\% pada pasien GGK yang menjalani HD dan kulit kering terjadi sebanyak 50-100\% pada pasien dengan dialysis yang sering muncul pada ekstermitas bawah dan lengan bawah. Pasien yang mengalami kulit kering (xerosis) tidak selalu menderita gatal jika mereka melakukan rehidrasi dan melembabkan kulitnya dengan baik (Mettang, 2016). 
Salah satu mekanisme yang menyebabkan pruritus yaitu kulit kering. Kulit kering dijelaskan pada sebagian besar pasien dengan Gagal Ginjal dan diduga sebagai faktor patogrnik yang signifikan pada pruritus dan dapat menambah intensitas gatal pada pasien GGK. Penelitian (Kolla et al., 2012) yang dilakukan sebanyak 52\% pasien yang menjalani HD ditemukan kulit kering. Kulit kering yang muncul pada pasien GGK dengan hemodialysis biasanya disebabkan karena atrofi kelenjar sebasea, gangguan fungsi sekresi eksternal, dan gangguan hidrasi stratum korneum (Kolla et al., 2012). Kulit kering pada pruritus juga dapat disebabkan karena retensi vitamin A akibat berkurangnya fungsi ginjal untuk mengeluarkan zat yang tidak dibutuhkan oleh tubuh., sehingga vitamin A akan terakumulasi di jaringan subkutan. Vitamin yang terlalu berlebihan akan menyebabkan atropi kelenjar sebaseus dan kelenjar keringat sehingga kulit menjadi kering dan gatal. Pasien HD di RSUD Buleleng berjumlah 120 orang dibagi menjadi dua shift yaitu pagi dan sore dengan 22 unit mesin HD. Tujuan dari penelitian ini adalah untuk mengetahui gambaran tingkat kelembaban kulit pada pasien Gagal Ginjal Kronik yang menjalani Hemodialisis di RSUD Buleleng.

\section{METODE}

Penelitian ini merupakan penelitian kuantitatif dengan menggunakan desain metode deskriptif cross sectional. Populasi penelitian ini adalah pasien GGK yang menjalani HD regular di RSUD Buleleng. Pengambilan sampel menggunakan teknik simple random sampling dengan jumlah 52 responden. Kriteria inklusi penelitian ini adalah pasien yang sedang menjalani HD regular 2x dalam seminggu. Kriteria eksklusi penelitian ini adalah pasien dengan HD cito, pasien yang mengalami penurunan kesadaran, pasien wanita yang sudah memasuki menopause, pasien yang travelling $\mathrm{HD}$, pasien yang mengalami luka atau infeksi sekunder pada kulit.

Alat pengumpulan data yang digunakan yaitu alat untuk mengukur kelembaban kulit Skin Moisture Analyzer dengan jenis SK-IV Digital Moisture Monitor For Skin. Hasil dari pengukuran kelembaban kulit ini yaitu 0-35\% kulit kering, 36-45\% kulit normal dan 46-100\% kulit lembab. Alat ukur kelembaban kulit ini sebagai instumen 
presisi yang dirancang khusus, produk ini menggunakan teknologi Bioelectrical Impedance Analysis (BIA) terbaru, dengan pendekatan pengukuran non-destruktif. Setelah data terkumpul, data dianalisis menggunakan SPSS dengan uji univariat untuk melihat distribusi frekuensi.

\section{HASIL}

Responden yang diteliti adalah pasien GGK yang menjalani HD regular $2 \mathrm{x}$ seminggu dengan gambaran karakteristik mencakup usia, jenis kelamin, pendidikan, pekerjaan dan lama HD. Berdasarkan tabel 1 diketahui bahwa mayoritas responden (38,4\%) berada pada kategori berusia 30-45 tahun dengan jumlah responden laki-laki lebih banyak $(69,2 \%)$. Jenjang pendidikan responden sebagian besar berada pada pendidikan menengah $(42,3 \%)$ dan responden tidak bekerja sebanyak 10 responden (19,2\%). Selanjutnya, lama HD sebagian besar selama 0-5 tahun yaitu sebanyak 75\%. Berdasarkan tabel 2 tingkat kelembaban kulit pasien GGK yang menjalani Hemodialisis di RSUD Buleleng didapatkan bahwa seluruh responden didapatkan kulit kering (100\%). Pasien yang menjalani HD selama kurang lebih 5 tahun telah mengalami kulit kering. Keluhan yang disampaikan pasien yaitu gatal pada kulit dimana pemicu terjadinya gatal adalah kulit kering. Gatal pada kulit itu juga berdampak pada kualitas tidur pasien, rasa gatal yang dialami kerap muncul pada malam hari. Kelelahan dan sulit tidur berdampak negative terhadap pekerjaan, aktivitas, pola gizi, kehidupan seksual dan hubungan keluarga. Kemajuan terkini dalam teknologi hemodialysis dapat memperpanjang umur pasien yang menjalani dialysis, akan tetapi terapi tersebut dapat menyebabkan beberapa masalah fisik dan mental. 
Tabel 1 Karakteristik responden GGK di Ruang Hemodialisa RSUD Buleleng

\begin{tabular}{lll}
\hline Karakteristik & Jumlah (n) & Presentase (\%) \\
\hline Usia (tahun) & & \\
Usia 30-45 & 20 & 38.4 \\
Usia 46-55 & 17 & 32.6 \\
Usia 56-65 & 17 & 32.6 \\
\hline Jenis Kelamin & & \\
Laki-laki & 36 & 69.2 \\
Perempuan & 16 & 30.7 \\
\hline Pendidikan & & \\
Tidak sekolah & 1 & 1.92 \\
Pend. Dasar & 21 & 40.3 \\
Pend. Menengah & 22 & 42.3 \\
Pend. Tinggi & 8 & 15.3 \\
\hline Pekerjaan & & \\
Tidak bekerja & 10 & 19.2 \\
IRT & 7 & 13.4 \\
Petani & 7 & 13.4 \\
Pedagang & 8 & 15.3 \\
Guru & 4 & 7.69 \\
Wiraswasta & 7 & 13.4 \\
Polisi & 1 & 1.92 \\
PNS & 1 & 1.92 \\
Lainnya & 7 & 13.4 \\
\hline Lama HD (tahun) & & \\
0-5 & 39 & 75 \\
6-10 & 11 & 21.1 \\
$>10$ & 2 & 3.84 \\
\hline
\end{tabular}

Tabel 2 Tingkat kelembaban kulit pasien GGK yang menjalani Hemodialisis di RSUD Buleleng.

\begin{tabular}{lll}
\hline Tingkat kelembaban kulit & Jumlah (n) & Persentase (\%) \\
\hline Kering & 52 & $100 \%$ \\
\hline Normal & - & - \\
\hline Lembab & - & - \\
\hline
\end{tabular}

\section{PEMBAHASAN}

Berdasarkan karakteristik responden berdasarkan usia, responden terbanyak memiliki umur 30-45 tahun sebanyak 20 responden $(38,4 \%)$ yang merupakan usia produktif, dimana perubahan pola makan dan sering mengkonsumi minuman suplemen 
sering dilakukan pada usia ini. Sejalan dengan penelitian (Alfiyanti, Setyawan, Argo, \& Kusuma, 2014) dimana sebagian besar responden pada kategori dewasa. GGK banyak terjadi pada usia dewasa, hal ini dipengaruhi oleh gaya hidup orang dewasa yaitu sering mengkonsumsi minuman berenergi agar tidak mudah cepat lelah dan pola makan yang tinggi lemak (Rismaharini, 2013). Menurut Yovita (2014) didalam minuman berenergi mengandung taurin, kafein, elektrolit seperti kalium, natrium, vitamin $\mathrm{C}$ dosis yang tinggi dan bicarbonate. Zat-zat tersebut nantinya akan dibuang melalui ginjal dan mempengaruhi keasaman urin, serta bisa memicu metabolism berlebih. Kadar yang berlebih tersebut apabila tidak diseimbangkan dengan konsumsi air putih serta kondisi ginjal dan jantung yang baik maka akan mengakibatkan gangguan pada fungsi ginjal dan hipertensi. Dalam penelitian (Kolla et al., 2012) didapatkan sebanyak 52\% pasien yang menjalani HD didapatkan kulit kering (xerosis). Kulit kering yang muncul pada pasien GGK dengan hemodialisis biasanya disebabkan karena atrofi kelenjar sebasea, gangguan fungsi sekresi eksternal, dan gangguan hidrasi stratum korneum. Kulit kering pada pasien dengan hemodialisis yang pruritus mempunyai hidrasi lebih rendah dibandingkan pasien hemodialisis tanpa keluhan pruritus (Roswati, 2013). Xerosis adalah gejala yang sering terjadi pada pasien dengan dialysis yang terjadi antara $50-100 \%$. Paling sering muncul pada ekstremitas bawah dan lengan bawah. Telah dilaporkan bahwa pruritus terkait CKD lebih umum dan lebih parah pada pasien dengan xerosis. Namun, pasien dengan xerosis tidak selalu menderita gatal jika mereka melakukan rehidrasi dan melembabkan kulitnya dengan baik. Jadi kemungkinan xerosis menambah intensitas gatal jika terkait dengan CKDaP(Chronic Kidney Disease associated Pruritus) (Mettang, 2016).

Jenis kelamin pada penelitian ini sebagian besar berada pada jenis kelamin laki-laki yaitu 36 responden (69,2\%). Hal ini didukung dengan penelitian Melastuti, dimana frekuensi terbesar pada pasien dengan hemodialysis berjenis kelamin laki-laki. Jenis kelamin laki-laki banyak menjalani hemodialysis karena sebagian besar laki-laki suka mengkonsumsi minuman beralkohol serta kebiasaan suka mengkonsumsi makanan jenis kacang-kacangan yang tidak diimbangi dengan minum air putih.

Hasil penelitian ini menunjukkan bahwa distribusi frekuensi terbesar yaitu 
responden dengan pendidikan menengah sebanyak 22 responden (42,3\%). Penelitian ini sejalan dengan Bayhakki (2015) didapatkan pendidikan paling banyak responden dengan pendidikan SMA $(48,6 \%)$. Penderita gagal ginjal kronik yang memiliki pendidikan yang tinggi akan mempunyai pengetahuan yang luas. Hal ini memungkinkan penderita untuk dapat mengontrol dirinya dalam mengatasi masalah yang dihadapi, mempunyai rasa percaya diri yang tinggi, berpengalaman dan mudah mengerti dengan apa yang dianjurkan petugas kesehatan.

Lama menjalani hemodialysis, sebagian besar responden menjalani HD selama 0-5 tahun sebanyak 39 responden (75\%). Sejalan dengan penelitian (Melastuti, Erna., Nafsiah, Hayatun., Fachrudin, 2018) menunjukkan distribusi frekuensi terlama berada pada rentang 29-52 bulan sebesar 36,7\%. Semakin lama durasinya secara otomatis akan mempengaruhi frekuensi hemodialisis dan dapat menjadi faktor pemicu ketidakpatuhan, untuk frekuensi dalam menjalani hemodialisis yang berbeda ada yang menjalani sekali setiap minggunya pada kondisi stadium gagal ginjal awal dan minimal 2 kali seminggu pada kondisi gagal ginjal stadium akhir (Melastuti, Erna., Nafsiah, Hayatun., Fachrudin, 2018).

Hasil penelitian ini menunjukkan distribusi frekuensi terbesar yaitu responden yang tidak bekerja sebanyak 10 responden (19,2\%). Menurut Notoatmodjo (2010) seseorang yang tidak mempunyai penghasilan atau penghasilan rendah akan berhubungan dengan pemanfaatan pelayanan kesehatan maupun pencegahan. Seseorang kurang memanfaatkan pelayanan kesehatan yang ada mungkin karena tidak mempunyai cukup uang untuk membeli obat atau membayar transportasi.

Gambaran kulit pada pasien GGK yang menjalani hemodialysis, semua pasien mengalami kulit kering (100\%) yang berada pada rentang nilai kelembaban kulit 0$35 \%$. Pada pasien yang menjalani HD karena GGK, berbagai lesi kulit akan muncul, dimana yang paling umum yaitu kulit kering. Gagal ginjal kronik dapat menyebabkan perubahan pada kelenjar keringat dan kelenjar minyak yang menyebabkan kulit menjadi kehilangan kemampuan alami untuk melembabkan diri. Kondisi ini dapat juga disebabkan dari perubahan metabolisme pada GGK, yang saling berkaitan dengan volume cairan dari pasien yang menjalani dialisis (Perry, Anne Griffin., Potter, Patricia 
A., Stockert, Patricia A., Hall, 2013).

\section{SIMPULAN}

Kulit kering yang muncul pada pasien GGK dengan hemodialysis biasanya disebabkan karena atrofi kelenjar sebasea, gangguan fungsi sekresi eksternal dan gangguan hidrasi stratum korneum. Kulit kering pada pasien dengan hemodialysis yang pruritus mempunyai hidrasi lebih rendah dibandingkan pasien hemodialysis tanpa keluhan pruritus.

\section{DAFTAR PUSTAKA}

Alfiyanti, N. E., Setyawan, D., Argo, M., \& Kusuma, B. (2014). Pada pasien Gagal Ginjal Kronik yang menjalani hemodialisis DI. Jurnal Ilmu Keperawatan Dan Kebidanan, 0.

Combs, S. A., Teixeira, J. P., \& Germain, M. J. (2015). Pruritus in Kidney Disease. Seminars in Nephrology, 35(4), 383-391. https://doi.org/10.1016/j.semnephrol.2015.06.009

Kolla, P. K., Desai, M., Pathapati, R. M., Valli, B. M., Pentyala, S., Reddy, G. M., \& Rao, A. V. M. (2012). Cutaneous Manifestations in Patients with Chronic Kidney Disease on Maintenance Hemodialysis. ISRN DErmatology, 2012, 1-4. https://doi.org/10.5402/2012/679619

Melastuti, Erna., Nafsiah, Hayatun., Fachrudin, A. (2018). Gambaran Karakteristik Pasien Hemodialisis di Rumah Sakit Islam Sultan Agung Semarang. Jurnal Ilmiah Kesehatan Rustida, 4(2), 518-525.

Mettang, T. (2016). Pruritus. (S. Misery, Laurent \& Stander, Ed.) (Second Edi). London: Springer.

Perry, Anne Griffin., Potter, Patricia A., Stockert, Patricia A., Hall, A. M. (2013). Fundamental of Nursing (Eighth Edi). St. Louis, Missouri: Elsevier Mosby.

Roswati, E. (2013). Pruritus pada Pasien Hemodialisis. Cermin Dunia Kedokteran, 40(4), 260 264.

Simonsen, E., Komenda, P., Lerner, B., Askin, N., Bohm, C., Shaw, J., Rigatto, C. (2017). Treatment of Uremic Pruritus: A Systematic Review. American Journal of Kidney Diseases, 70(5), 638-655. https://doi.org/10.1053/j.ajkd.2017.05.018 